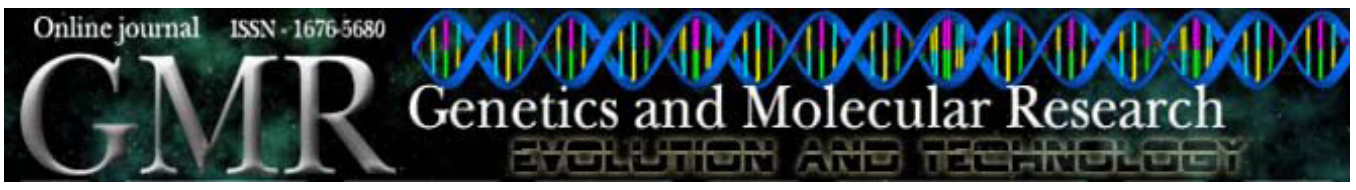

\title{
The number of reproductive workers in highly eusocial Hymenoptera: monogyny and monandry
}

\author{
P.S. Santos-Filho ${ }^{1}$, A. Eterovic ${ }^{1,2}$, A.M.P. Kleinert ${ }^{1}$, \\ V.L. Imperatriz-Fonseca ${ }^{3}$ \\ ${ }^{1}$ Departamento de Ecologia, Instituto de Biociências, \\ Universidade de São Paulo, São Paulo, SP, Brasil \\ ${ }^{2}$ Centro de Ciências Naturais e Humanas, \\ Universidade Federal do ABC, Santo André, SP, Brasil \\ ${ }^{3}$ Departamento de Biologia, Faculdade de Filosofia, \\ Ciências e Letras de Ribeirão Preto, \\ Universidade de São Paulo, Ribeirão Preto, SP, Brasil \\ Corresponding author: P.S. Santos-Filho \\ E-mail: pssantos@ib.usp.br
}

Genet. Mol. Res. 8 (2): 557-570 (2009)

Received December 12, 2008

Accepted January 26, 2009

Published May 19, 2009

\begin{abstract}
Haplodiploidy results in relatedness asymmetries between colony members of highly eusocial Hymenoptera. As a consequence, queen and reproductive workers are more related to their own sons than to each other's male offspring. Kin selection theory predicts multiple optima in male parentage: either the queen or the workers should produce all the males. Nevertheless, shared male parentage is common in highly eusocial hymenopterans. An inclusive fitness model was used to analyze the effect of the number of reproductive workers on male parentage shared by the queen and laying workers by isolating the male component from an inclusive fitness equation using the equal fitness through male condition for each pairwise combination of the three female classes comprised of the queen, laying workers and non-laying workers. The main result of the theoretical analyses showed that the fraction of males produced by workers increases asymptotically with the number of laying workers at an increasingly diminishing rate, tending to an asymptotic value of 0.67 . In addition, as the number of
\end{abstract}


laying workers increases, the share of male parentage converges to that of non-laying workers. The diminishing return effect on male parentage share depending on the number of reproductive workers leads us to expect the number of reproductive workers to be relatively small in a stingless bee colony, even in the absence of productivity costs. The available data confirms this hypothesis, as there is an unusually small number of reproductive workers in stingless bee colonies.

Key words: Reproductive workers; Eusocial Hymenoptera; Male parentage; Inclusive fitness; Kin conflict

\section{INTRODUCTION}

The highly eusocial perennial Hymenoptera show a remarkable level of intra-colony cooperation (Wilson, 1971). However, even in colonies that have a simple kin structure, characterized by monogyny and monandry, haplodiploidy results in relatedness asymmetries between members of the colony, leading to genetic conflicts of interest regarding investment in offspring (Hamilton, 1964, 1972). If workers are sterile, the high level of relatedness with their sisters $(r=0.75)$ as opposed to their brothers $(r=0.25)$ would lead us to expect that workers would prefer to invest preferentially in raising sisters and hence workers would prefer an equilibrium sex investment M:F of 0.25:0.75 (Hamilton, 1972; Trivers and Hare, 1976; Benford, 1978). The queen, being equally related to sons $(\mathrm{r}=0.50)$ and daughters $(\mathrm{r}$ $=0.50$ ) would prefer an equilibrium sex ratio of M:F of 0.50:0.50 (Hamilton, 1972; Trivers and Hare, 1976; Benford, 1978). Hence kin selection theory predicts a potential conflict between queen and workers over investment in the sexes of offspring. In addition, when workers are reproductive, they are more related to their sons $(r=0.50)$ and nephews $(r=0.375)$ than to their brothers $(r=0.25)$, which led Hamilton (1972) to state that "if circunstances allow, ...[workers would be]...inclined to replace the queen's male eggs with their own, whilst the queen would, if possible, produce all the males". Therefore, whenever workers are reproductive a potential conflict over male parentage is also expected.

Kin selection theory is particularly effective at predicting the optimal sex ratios and male parentage share under the specific assumption that one particular party (e.g., queen or workers) has the power to enforce its own optimum and hence achieve total control over the sex ratio or male parentage. However, as theory produces multiple optima, each corresponding to the genetic interests of a given party, it does not allow us to predict which party will obtain total control (see Beekman et al., 2003; Beekman and Ratnieks, 2003). For instance, Trivers and Hare (1976) built subtle and complex arguments combining Fisher's (1958) sex investment theory, Hamilton's $(1964,1972)$ kin selection theory and Trivers' (1974) parent-offspring theory, assuming that workers had the power to capitalize on relatedness asymmetries, and hence would enforce a female-biased sex ratio in haplodiploid hymenopterans. Their theoretical work spawned numerous publications on sex ratios in Hymenoptera (reviews by Herbers, 1979; Nonacs, 1986; Boomsma, 1989; Pamilo, 1990; Bourke and Franks, 1995; Chapuis and Keller, 1999; Mehdiabadi et al., 2003), and conflict over sex ratio is still one of the most active areas in evolutionary theory (e.g., Matessi and Eshel, 1992; Roisin and Aron, 2003; Reuter et al., 2004; Helms et al., 2005). 
The initial work on conflict over male parentage was carried out within the context of conflict over sex allocation, due to its being one factor, amongst others, namely, polygyny, polyandry, inbreeding, and queen identity after replacement, which may affect the expected optima (Benford, 1978; Pamilo, 1991b; Ratnieks and Boomsma, 1997). Recently, conflict over male parentage has emerged as an almost independent area of research, particularly in relation to worker policing (see Foster and Ratnieks, 2001; Hammond and Keller, 2004; Wenseleers and Ratnieks, 2006).

Evolutionarily, the queen has won the conflict over male parentage in several species of eusocial Hymenoptera. As a consequence, there are seven genera of ants (Atta, Linepithema, Monomorium, Pheidole, Pheidologeton, Tetramorium, and Solenopsis) and three genera of stingless bees (Duckeola, Frieseomelitta and Tetragonula) in which workers have sterile ovaries (Tóth et al., 2004; Ratnieks et al., 2006). However, one may expect that when one party has acquired complete control over male parentage, that selection pressures on the other party will be strong and hence, evolutionarily, control may shift between parties (Reuter and Keller, 2001). Interestingly, there are no unambiguous examples in which workers have completely achieved control over male parentage (Hammond and Keller, 2004; Wenseleers and Ratnieks, 2006). On the other hand, there are many examples of species in which complete control over male parentage has been achieved by neither queen nor workers (Hammond and Keller, 2004; Wenseleers and Ratnieks, 2006).

Worker reproduction has been theoretically investigated (e.g., Lin and Michener, 1972; Oster and Wilson, 1978; Cole, 1986; Woyciechowski and Lomnicki, 1987; Bourke, 1999; Wenseleers et al., 2004a,b). One common feature of these models is the assumption of a productivity cost to the colony associated with worker reproduction (but see Hammond et al., 2003).

Our research was stimulated by the general observation that the number of reproductive workers in colonies of stingless bee species is uniformly small in those species in which it has been counted (Kerr and Vencovski, 1982; Cepeda, 2006; Koedam et al., 2005). The models developed by Wenseleers et al. (2004a,b) focus on the fraction of workers who should activate their ovaries, but not directly on the number of reproductive workers. Admittedly, the model here utilized, based on Pamilo (1991a,b), to investigate the relationship between the number of reproductive workers and the male parentage share between queen and laying workers is too stylized to reflect the actual biology of stingless bees, but should suffice to provide an initial sketch of the problem.

\section{MATERIAL AND METHODS}

\section{Model}

The organism envisaged is a perennial eusocial hymenopteran species with a very large number of colonies, comprising an outbreeding population. There is one queen in each colony (monogyny), which is mated with one male (monandry). Thus, the kin structure of each colony is very simple. The sexuals (queens and males) are produced once a year during a short period. The mating is random (panmitic), and once the queens mate they found colonies independently. There is no local mate competition (LMC) and no local resource competition (LRC). These assumptions are commonly used in theoretical modeling (e.g., Ratnieks and Reeve, 1992; Bourke and Chan, 1999). 
There is a linear relationship between investment in each sex and the reproductive returns (Frank, 1987; Pamilo, 1991a). In addition, there is an equal cost of production of each male and female (Benford, 1978); this implies no sexual dimorphism between daughter queens and males and allows us to use numerical investment directly.

The inclusive fitness model structure used is that of Pamilo (1991a,b) as it allows us to consider the reproductive output of each colony (see Crozier and Pamilo, 1996). The inclusive fitness of each agent is separately considered.

The inclusive fitness of an agent $(i)$ reads as:

$$
W_{i}=N \cdot\left[\left(g_{i j} \cdot V_{F} \cdot \frac{x}{X}\right)+\left(g_{i j} V_{M} \cdot \frac{y}{Y}\right)\right]
$$

where $\mathrm{V}_{\mathrm{M}}$ and $\mathrm{V}_{\mathrm{F}}$ are the reproductive values of males and females, respectively. $\mathrm{N}$ is the total number of sexual offspring produced, and $g_{i j}$ is the regression relatedness between agent $(i)$ and offspring $(j)$, as shown in Table 1.

Table 1. Regression relatedness $\left(g_{i j}\right)$ between adults and offspring.
\begin{tabular}{lllll}
\hline Queen & Daughter & Son & & \\
& $g_{\mathrm{QD}}=1 / 2$ & $g_{\mathrm{QS}}=1$ & Grandson & \\
\hline Non-laying worker & Sister & Brother & $g_{\mathrm{QG}}=1 / 2$ & Nephew \\
& $g_{\mathrm{WS}}=3 / 4$ & $g_{\mathrm{WB}}=1 / 2$ & $g_{\mathrm{WN}}=3 / 4$ & \\
\hline Laying worker & Sister & Brother & Nephew & Son \\
\cline { 2 - 5 } & $g_{\mathrm{WS}}=3 / 4$ & $g_{\mathrm{WB}}=1 / 2$ & $g_{\mathrm{WN}}=3 / 4$ & $g_{\mathrm{LWS}}=1$ \\
\hline
\end{tabular}

The fraction of male sons (y) and daughter queens (x) in the colonies as well as the fraction of male sons $(\mathrm{Y})$ and daughter queens $(\mathrm{X})$ in the population are related as: $\frac{x}{X}=\frac{y}{Y}=1$.

Hence, the sex ratio of the colonies and of the population are in equilibrium, which is a common assumption used for large or infinite population size (e.g., Pamilo, 1991b; Boomsma and Grafen, 1991).

To examine worker reproduction, one considers three female classes within the colony, namely, the queen, laying workers and non-laying workers; consequently, separate inclusive fitness equations were built for each female class, based on Pamilo (1991a) and Crozier and Pamilo (1996). When there are no reproductive workers in a colony, the reproductive values do show a fixed relationship $\mathrm{V}_{\mathrm{F}}=2$. $\mathrm{V}_{\mathrm{M}}$ (e.g., Hamilton, 1972; Benford, 1978). However, the presence of reproductive workers modifies the reproductive value of males; for this reason it is better to keep the regression relatedness separate from the reproductive value (Benford, 1978; Boomsma and Grafen, 1991). Thus, the reproductive value of both sexes is modified by the fraction of males that are sons of workers ( $\Psi)$. Here we use Pamilo's (1991a) notation, and focus, instead of using the fraction of males that are queen's sons ( $p$ in Trivers and Hare, 1976; Benford, 1978; note that $p=1-\Psi$ ).

The reproductive value of females and males is given by:

$$
V_{M}=\left[1+\left(\frac{\Psi}{3-\Psi}\right)\right]
$$

(Equation 2) 


$$
V_{F}=\left[2-\left(\frac{\Psi}{3-\Psi}\right)\right]
$$

(Equation 3)

When males are produced by reproductive workers the relationship between reproductive values of females and males becomes $V_{\mathrm{F}}=(2-\Psi) \cdot V_{\mathrm{M}}$.

The general equations of the inclusive fitness of the queen $\left(\mathrm{F}_{\mathrm{Q}}\right)$, non-laying worker $\left(\mathrm{F}_{\mathrm{NLW}}\right)$ and laying worker $\left(\mathrm{F}_{\mathrm{LW}}\right)$, i.e., of each female class, is given by, respectively:

$$
\begin{aligned}
& F_{Q}=N \cdot\left[\left(g_{Q D} \cdot V_{F} \cdot \frac{x}{X}\right)+\left(g_{Q M} \cdot V_{M} \cdot \frac{y}{Y}\right)\right] \\
& F_{N L W}=N \cdot\left[\left(g_{W S} \cdot V_{F} \cdot \frac{x}{X}\right)+\left(g_{W M} \cdot V_{M} \cdot \frac{y}{Y}\right)\right] \\
& F_{L W}=N \cdot\left[\left(g_{W S} \cdot V_{F} \cdot \frac{x}{X}\right)+\left(g_{W M} \cdot V_{M} \cdot \frac{y}{Y}\right)\right]
\end{aligned}
$$

Thus, one replaces the specific regression relatedness for each adult-offspring pair and

\begin{tabular}{|c|c|c|c|c|c|c|c|}
\hline \multirow[t]{2}{*}{ Queen } & \multicolumn{3}{|c|}{ Daughter } & \multirow{2}{*}{$\begin{array}{c}\text { Son } \\
g_{\mathrm{QS}} V_{\mathrm{M}}(1-\psi)\end{array}$} & \multirow{2}{*}{\multicolumn{2}{|c|}{$\frac{\text { Grandson }}{g_{\mathrm{QG}} V_{\mathrm{M}} \psi}$}} & \\
\hline & $F_{\mathrm{Q}}=$ & $g_{\mathrm{QD}} V_{\mathrm{F}}$ & + & & & & \\
\hline \multirow[t]{2}{*}{ Non-laying worker } & & Sister & & Brother & & Nephew & \\
\hline & $F_{\mathrm{NLW}}=$ & $g_{\mathrm{WS}} V_{\mathrm{F}}$ & + & $g_{\mathrm{WB}} V_{\mathrm{M}}(1-\psi)$ & + & $g_{\mathrm{WN}} V_{\mathrm{M}} \psi$ & \\
\hline \multirow[t]{2}{*}{ Laying worker } & & Sister & & Brother & & Nephew & Son \\
\hline & $F_{\mathrm{LW}}=$ & $g_{\mathrm{WS}} V_{\mathrm{F}}$ & + & $g_{\mathrm{WB}} V_{\mathrm{M}}(1-\psi)$ & + & $g_{\mathrm{WN}} V_{\mathrm{M}} \psi(1-w)$ & $g_{\mathrm{LWS}} V_{\mathrm{M}} \psi w$ \\
\hline
\end{tabular}
the reproductive value for males and females into the general equations, in addition considering the equilibrium of the sex ratio of colonies and population $(x / X=y / Y=1)$ to obtain for each female class the equations shown in Table 2.

Regression relatedness $\left(g_{i j}\right)$ as in Table 1. Reproductive values of each sex varies with the fraction of male eggs laid by workers $(\psi)$ : (females $V_{\mathrm{F}}=2-[\psi /(3-\psi)]$; males $\left.V_{\mathrm{M}}=1+[\psi /(3-\psi)]\right)$. $w$ is the proportion of male eggs laid by workers that are sons of a focal worker (1-w is the proportion of her nephews). Colonies in sex ratio equilibrium with respect to the population $(\mathrm{x} / \mathrm{X}=\mathrm{y} / \mathrm{Y}=1)$.

Additional assumptions were utilized in the analyses: i) sex ratio is unchanged by conflict over male parentage, and ii) the male parentage share by workers $(\Psi)$ does not influence the total number of offspring $(\mathrm{N})$ produced. Also, iii) all colonies were assumed to have an equal amount of resources to produce offspring and hence $\mathrm{N}$ is a constant, unspecified number. 


\section{Male parentage share and the number of reproductive workers}

We analyzed the influence of the number of reproductive workers on the expected male parentage share, first modifying the general inclusive fitness equation by allowing $\mathrm{N}=$ $\mathrm{N}_{\mathrm{Q}}+\mathrm{N}_{\mathrm{M}}$, which yields, for $(\mathrm{x} / \mathrm{X}=\mathrm{y} / \mathrm{Y}=1)$ :

$$
W_{i}=N_{Q} \cdot\left(g_{i j} \cdot V_{F} \cdot 1\right)+N_{M} \cdot\left(g_{i j} \cdot V_{M} \cdot 1\right)
$$

(Equation 7)

Next, we isolated the male allocation component $C_{i j}=g_{i j} . V_{M}$ from the general inclusive fitness equation, and considered $\mathrm{N}_{\mathrm{M}}$ as fixed for all colonies. In this way we obtained the male allocation component for each female class. The male allocation component for the laying worker is based on Crozier and Pamilo (1996):

$$
\begin{gathered}
C_{Q M}=\left[(1-\Psi) \cdot g_{Q S}+\Psi \cdot g_{Q G}\right] \\
C_{N L W M}=\left[(1-\Psi) \cdot g_{W B}+\Psi \cdot g_{W N}\right] \\
C_{L W M}=\left[\Psi \cdot g_{W S} \cdot\left(\frac{1}{N_{W}}\right)+\Psi \cdot g_{W N} \cdot\left(\frac{N_{w}-1}{N_{W}}\right)+(1-\Psi) \cdot g_{W B}\right]
\end{gathered}
$$

To investigate the effect of the number of laying workers $\left(\mathrm{N}_{\mathrm{W}}\right)$ on male parentage share $(\Psi)$ we assumed that all female classes would obtain equal fitness through males (henceforth EFTM). The equal fitness condition is commonly used in population genetics to examine equilibrium conditions for allele frequencies. Admittedly, this is a relatively weak equilibrium condition (Frank, 1998), and it does not satisfy a more strict condition that makes it possible to be invalidated for a strategy (evolutionarily stable strategy).

Hence we considered each pairwise female class as obtaining equal fitness through males, as follows: $\mathrm{C}_{\mathrm{QM}}=\mathrm{C}_{\mathrm{NLWM}}, \mathrm{C}_{\mathrm{QM}}=\mathrm{C}_{\mathrm{LWM}}$, and $\mathrm{C}_{\mathrm{NLWM}}=\mathrm{C}_{\mathrm{LWM}}$. The reproductive value for males is the same for all female classes and hence it is ignored.

The analyses above imply additional assumptions: i) equal contribution of each reproductive worker, i.e., there is no reproductive skew; ii) the number of males produced is independent of the fraction of males that are workers' sons, and iii) the number of male offspring is independent of the number of reproductive workers.

A crucial assumption in the analyses is that the presence of workers imposes no cost, or a negligible cost at most, for colony productivity (see Wenseleers et al., 2004a,b).

\section{RESULTS}

\section{Male parentage share and the number of reproductive workers}

The algebraic solution of the equal fitness through male condition for each pairwise combination of female classes yields the following results, when one solves the equations for $\Psi$. 


$$
\begin{gathered}
\mathrm{C}_{\mathrm{NLWM}}=\mathrm{C}_{\mathrm{LWM}} \Psi=0.00 \\
\mathrm{C}_{\mathrm{QM}}=\mathrm{C}_{\mathrm{NLWM}} \Psi=0.6667 \\
\mathrm{C}_{\mathrm{QM}}=\mathrm{C}_{\mathrm{LWM}} \Psi=\frac{2 \cdot N_{W}}{1+3 \cdot N_{W}}
\end{gathered}
$$

Therefore, in the first two resulting equations, which both involve non-laying workers, the expected male parentage share, under the assumption of equal fitness through males for parties, is independent of the number of reproductive workers. The pairwise combination involving the queen and the laying worker results in an equation that is a function of the number of laying workers.

The male allocation component plotted against the male parentage share for $\mathrm{N}_{\mathrm{w}}=1$ is shown in Figure 1, allowing us to visualize the points of equal fitness for each pair of female classes simultaneously. It is noteworthy that for $\mathrm{N}_{\mathrm{w}}=1$, the equal fitness through male condition for the queen and one laying worker yields $\Psi=0.5000$, i.e., equal male share, and that it is independent of the number of reproductive workers $\left(\mathrm{N}_{\mathrm{w}}\right)$. When $\Psi=0$ and all males are produced by the queen, the equilibrium sex ratio of workers is $\mathrm{M}=0.25$, and hence $\mathrm{M}: \mathrm{F}=$ 0.25:0.75, the preferred equilibrium investment ratio of non-laying workers.

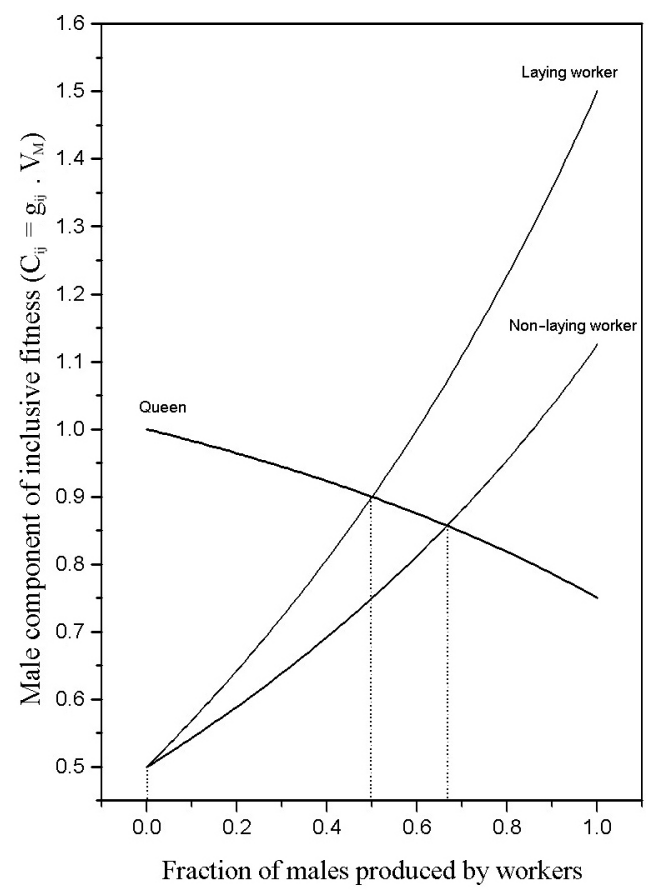

Figure 1. Relationship between the male component of inclusive fitness $\left(C_{i j}=g_{i j} \cdot V_{M}\right)$ and the fraction of males produced by workers for the queen, one laying worker $\left(\mathrm{N}_{\mathrm{w}}=1\right)$ and one non-laying worker. The dotted lines show the male parentage share for each pairwise combination of female classes. 
In Figure 2, the male parentage share is plotted against the number of reproductive workers; it is clear that $\Psi$ increases in a diminishing return fashion with increasing $\mathrm{N}_{\mathrm{w}}$. There is an asymptotic tendency of male parentage share towards an ultimate asymptote of $\Psi=0.67$. For instance, at $\mathrm{N}_{\mathrm{W}}=1000$ the value of $\Psi=0.6664$. Therefore, as the number of reproductive workers increases, the male parentage share between the queen and reproductive workers becomes very similar to the male parentage share between the queen and one non-laying worker, which is $\Psi=0.6667$.

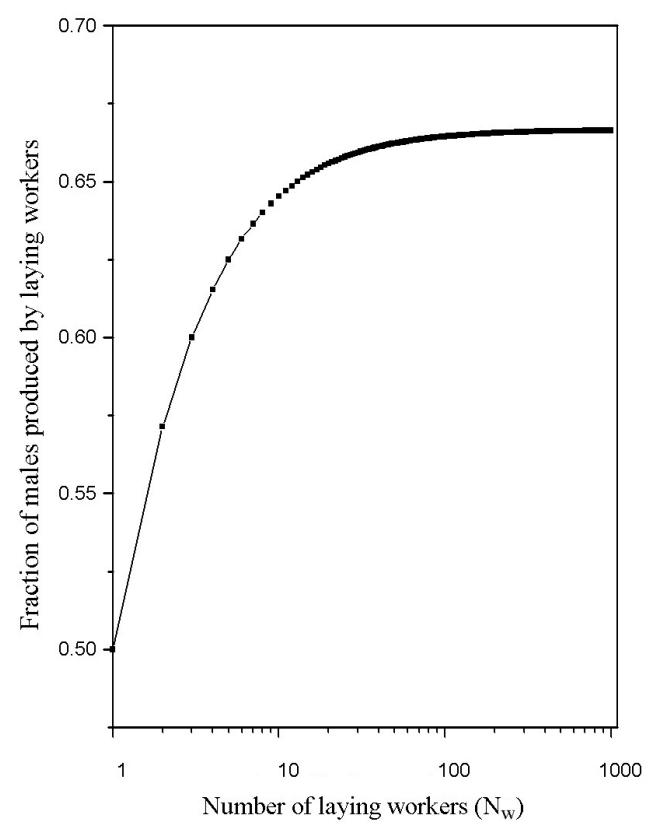

Figure 2. Relationship between the fraction of males produced by laying workers and the number of reproductive workers, resulting from applying the condition of equal fitness through males for the queen and laying worker. Note that male parentage share tends to the asymptotic value 0.67 .

\section{DISCUSSION}

The eusocial hymenopteran species that best fit the model's assumptions are ants (see Wenseleers and Ratnieks, 2006). Nonetheless, we attempted to apply the model to stingless bees. Thus, it becomes necessary to examine the validity of the assumptions because predictions crucially depend on them, though models may be robust, to a certain degree, of violation of assumptions.

All stingless bee species, with the exception of Melipona bicolor, are monogynic. Monandry has been demonstrated for several stingless bee species (Peters et al., 1999; Strassmann, 2001). Thus, the simple kin structure that is assumed is valid for the great majority of stingless bees.

Despite limited information, population sizes of stingless bees of the order of at least one hundred colonies have been reported (Kerr and Venkovsky, 1982; Inoue et al., 1993; Eltz et al., 2002, 2003; Cameron et al., 2004). Random mating has been demonstrated for some species (Cameron et al., 2004; Paxton, 2005; Boomsma et al., 2005). 
Nest foundation in stingless bees is through swarming (Nogueira Neto, 1954; Inoue et al., 1984); hence the assumption of independent colony foundation is invalid. As a consequence, there may occur either local resource competition between daughter nests due to their proximity to the mother nest (Bourke and Franks, 1995; Crozier and Pamilo, 1996) and/or local mate competition among daughter queens to head a swarm (Bourke and Ratnieks, 1999). The occurrence of LRC and LMC will lead to non-linear fitness return functions for queens and males, thus violating the assumption of linear fitness returns for each sex (Frank, 1987). It is well known that LMC and LRC render algebraic analysis very complex (Pamilo 1991a; Boomsma and Grafen, 1991). However, males may have linear fitness returns after all because selection favors the greatest possible number of males. Thus, the analysis of the effect of the number of reproductive workers on male parentage share would not be affected by the nonlinear fitness returns of gynes as they were removed from analysis; selection generally favors a relatively small number of gynes in swarming species (Bourke and Ratnieks, 1999). However, our analytical results should be examined with these caveats in mind.

It is conceivable that male parentage could affect the sex ratio; in fact this assumption was used by Wenseleers et al. (2004a,b). In our analysis, by making the colony sex ratio the same as in the population, without specifying the actual sex ratio, male parentage share could affect the colony's sex ratio, provided that population sex ratio is affected in a similar manner.

Initial theoretical work on reproductive workers implicitly assumed the absence of productivity costs to the colony (Trivers and Hare, 1976; Benford, 1978; Charnov, 1978; but see Lin and Michener, 1972). Here, absent or negligible colony productivity costs associated with the presence of reproductive workers were judged plausible based on several aspects of stingless bee biology, as discussed below.

Firstly, stingless bees generally have relatively large colonies, of the order of one hundred individuals to several thousands (Bourke, 1999; Tóth et al., 2004); conceivably only a large number of reproductive workers would substantially reduce the colony's productivity. The number of reproductive workers in stingless bee colonies is generally small. Beig (1972) found 23 laying workers, on average, per colony of Scaptotrigona postica. The estimated colony size of S. postica ranges from 5750 to 15,000 (Hammond and Keller, 2004; Tóth et al., 2004). Thus, reproductive workers comprise from 0.15 to $0.4 \%$ of the workers. Tambasco (1971) estimated laying workers per colony in Melipona quadrifasciata; considering an average of 585 workers per colony (Tóth et al., 2004), this means $0.68 \%$ of the workers. Kerr and Venkovsky (1982) reported only nine laying workers in M. quadrifasciata, thus the laying workers comprised $1.5 \%$ of the workers. Likewise, Koedam et al. (2007) counted 14 laying workers among 409 marked workers in an M. bicolor colony, i.e., laying workers comprised 3.4\%. Koedam et al. (2005) reported 24 laying workers in M. subnitida in colonies averaging 450 individuals; thus, they comprised $5 \%$ of the worker population.

The analysis of male parentage share showed that the fraction of workers' males increases at an increasingly diminishing rate with the number of laying workers. Hence, due to the diminishing return effect, laying workers, as a class, do not achieve a substantially larger male share, as their number increases indefinitely. Actually, as male share of laying workers approaches the asymptote, their male share converges towards that of a non-laying worker, because the effect of each worker's sons become negligibly small $\left(1 / \mathrm{N}_{\mathrm{w}}\right.$ as $\mathrm{N}_{\mathrm{w}}$ becomes very large; see Crozier and Pamilo, 1996). Hence a clear effect of the increasing number of reproductive workers on the male component of fitness of one focal laying worker is the relative devaluing of sons allied to the enhancing of the relative value of nephews. 
When the number of laying workers is small, the largest changes in male share are obtained. So, considering the transition from the absence of laying workers to the presence of one laying worker, under EFTM conditions, the male share shifts from nil to $50 \%$, a value already at $75 \%$ of the asymptote, and when the number of laying workers is about eight, male share has already reached $95 \%$ of the asymptotic value. The convergence of the male parentage share values as the number of laying workers increase leads to practically a single value for the queen and both laying and nonlaying workers. Therefore, at least with regard to male parentage share, the diminishing return effect associated with the number of reproductive workers leads us to expect the number of reproductive workers to be relatively small in a stingless bee colony, even in the absence of productivity costs. Indeed, the number of reproductive workers is not only unusually small, but also comprises a very small fraction of the total number of workers in stingless bee colonies, as shown above.

Secondly, an important aspect of worker reproduction is commonly neglected, that is their production of trophic eggs, which are fed to the queen (Koedam et al., 2005); hence they cannot be viewed as solely exploitative of the group's productivity. Thirdly, although males are costly (Velthuis et al., 2005; Santos-Filho et al., 2006), colonies produce them within relatively short periods, and hence may limit their production to high-resource availability periods (Tóth et al., 2004; Velthuis et al., 2005). Thus, the presence of reproductive workers is not expected to significantly reduce colony productivity, at least in terms of the number of males produced.

Nonetheless, stingless bee reproductive workers do less foraging and do engage in dominance squabbles, being mostly concerned with their own reproductive activities (Cepeda, 2006; Koedam et al., 2007). Thus, there is also support for a recent models' assumption that the presence of laying workers will lead to a decrease in colony productivity, and that inclusive fitness costs should favor reduced worker reproduction (Wenseleers et al., 2004a,b). There are several other hypotheses that attempt to explain why there is so much variation in male parentage share in Hymenoptera (see reviews by Tóth et al., 2004; Hammond and Keller, 2004; Velthuis et al., 2005; Wenseleers and Ratnieks, 2006).

The EFTM condition's main importance is allowing analysis of the behavior of male parentage and the effect of the number of reproductive workers at an evolutionarily significant and singular point, where each female class has exactly the same fitness through males. Thus, one may view the EFTM point as a sort of standardized experimental condition, in which fitness is maintained constant for all parties rather than being either an equilibrium point in the sense of evolutionary stability or an expected biological outcome.

There is no a priori reason why classes of females would seek an equal fitness situation rather than pursuing their own optima. The equal fitness principle only guarantees that at the EFTM point no class of individuals is achieving lower fitness than the other with respect to male share. Actually, selection should unrelentlessly push each party toward its own optimum; it is expected that both the queen and the laying workers will each develop evolutionarily strategies to obtain a larger male parentage share, and that the other party will develop strategies to prevent or to diminish the other party's male share. Hence, at any moment in evolutionary time, each party will have particular states of the enhancing strategies and of counter (diminishing) strategies, and practically any value of male parentage share can be expected, including the value associated with the EFTM point. However, there is no particular reason to expect parties to spend more time at EFTM than at any other point. One expectation is that selective forces will be increasingly stronger the further any given party is away from its optimum (see Reuter and Keller, 2001), which is the complete control of male production. 
It has already been pointed out that queens have evolutionarily obtained total male production in three stingless bee genera, which represents the resolution of the conflict (Ratnieks et al., 2006); but given that selection pressures should be greatest the furthest from the optimum, is this worker sterility irreversible? Also, as noted before, there are no clear cut examples of workers having achieved complete control of male production in all colonies of a stingless bee species. This asymmetry is puzzling, given that relatedness asymmetry leads to expect selection to act both on the queen and the workers equally in order to achieve their respective optima. Perhaps this asymmetry reflects intrinsic asymmetries in the power of the two female classes (Beekman and Ratnieks, 2003). The queen is a specialized egg-layer caste, with a long reproductive lifespan and high fecundity. Reproductive workers in the highly eusocial stingless bees are known for not being able to mate, so they can only lay haploid eggs, and have a relatively short reproductive life and low fecundity, but with pronounced interindividual variability in egg laying rates, i.e., reproductive skew. These may well be primary causes for the inherent asymmetry in the frequency with which the queen's and worker's optima in male parentage are observed.

The possibility of an intermediate equilibrium between the optima of the queen and of the workers regarding male parentage seems to depend on the costs in productivity to the colony; otherwise one might expect that, evolutionarily, the male parentage share will continuously oscillate between the optima of the two parties and at any particular moment the frequency distribution of male parentage share among colonies of a species would be described by a random distribution. In other words there would be no evolutionarily stable strategy at any intermediate male share. Indeed, in the related conflict over sex ratio between queen and workers, kin selection theory predicts different optima in the investment in the sexes for the queen and workers (Trivers and Hare, 1976; Benford, 1978; Oster and Wilson, 1978), and it has been suggested that there would be no evolutionarily stable strategy at intermediate sex ratios (Herbers, 1979). Nonetheless, by incorporating costs for sex ratio biasing intermediate optima can be found (e.g., Matessi and Eshel, 1992; Roisin and Aron, 2003; Reuter et al., 2004; Helms et al., 2005).

Although the EFTM point is not an evolutionarily stable biological outcome, it raises the interesting question as to whether queen and workers might be able to detect that they are obtaining equal fitness through male offspring. This is a problem similar to that involved in the evolution of split sex ratios, which demands that workers be able to measure intra-colony relatedness asymmetry, either directly somehow through genetic cues or indirectly through cues correlated with relatedness asymmetry (Boomsma and Grafen, 1990, 1991).

Workers are able to recognize diploid males in Melipona quadrifasciata, and can kill both males and the queen producing them (Kerr and Vencovsky, 1982). Hence workers can recognize haploid and diploid males. Consider a simple index of kin recognition efficiency RE $=\mathrm{G}_{\mathrm{ij}} / \mathrm{G}_{\mathrm{ik}}$, where $\mathrm{G}_{\mathrm{ij}}$ and $\mathrm{G}_{\mathrm{ik}}$ are the life for life relatedness between the agent $i$ attempting kin recognition and each one of the target classes of relatives, $j$ and $k$. The ratio RE is built by using as a numerator the smallest of these relatednesses, call it $\mathrm{G}_{\mathrm{ij}}$. The range of this index is between zero and one. A worker's relatedness to diploid males is $r=0.75$ and haploid males may comprise sons, brothers and nephews of the worker, yielding a mean relatedness of $r=0.375$. Hence $\mathrm{RE}=0.50$ is a level of recognition achieved by stingless bee workers. Note that the precise means by which kin recognition is made is not of concern here. It is reasonably well established that honey bee workers can distinguish full sisters $(r=0.75)$ from half sisters $(r=0.25)$, this 
implies an $\mathrm{RE}=0.33$ (Keller, 1997). The workers of Melipona panamica can distinguish sisters $(r=0.75)$ and nieces $(r=0.375)$, a recognition level of $R E=0.50$ (Inoue et al., 1999).

The EFTM assumption demands appropriate weighting of the classes of male offspring by relatedness. There are three categories of relatedness to consider: sons, brothers and nephews. Assume that both queen and workers can recognize sons and non-sons. Thus, for the queen there are her sons $(r=0.50)$, and the non-sons are grandsons $(r=0.25)$. The queen would not need any further refining kin recognition than $\mathrm{RE}=0.50(0.25 / 0.50)$. Workers would, accordingly recognize their sons $(\mathrm{r}=0.50)$, and the non-sons would comprise both brothers $(r=0.25)$ and nephews $(r=0.375)$. So, in order to evaluate self-fitness workers would need two levels of kin recognition: sons versus non-sons $(\mathrm{RE}=0.50)$ and brothers versus nephews $(\mathrm{RE}=0.67)$. However, if workers recognized brothers and nonbrothers, i.e., sons and nephews, they would be recognizing $r=0.25$ versus an average relatedness of $r=0.4375$, thus $R E=0.57$. Therefore, fitness evaluation requires the queen to be able to recognize sons and non-sons, and the workers to distinguish between brothers and non-brothers; these levels of recognition efficiency seem to be within the recognition abilities of bees. It is instigating that the modeling approach based on the idea of equal fitness through males yields, as a by-product, a testable hypothesis regarding the level of kin recognition by queen and workers with respect to male classes. Nonetheless, paraphrasing Grafen (1990), the ability of workers to recognize kin does not necessarily imply that workers use this ability to assess their own fitness.

Admittedly, the model that we utilized, based on Pamilo (1991a,b), to investigate the relationship between the number of reproductive workers and the male parentage share between queen and laying workers is too simplified to reflect the actual biology of stingless bees, but should suffice to provide an initial sketch of the problem.

\section{ACKNOWLEDGMENTS}

We dedicate this paper to Dr. Warwick Estevam Kerr. Research supported by FAPESP/ BIOTA, Process No. 04/15 801-0.

\section{REFERENCES}

Beekman M and Ratnieks FL (2003). Power over reproduction in social Hymenoptera. Philos. Trans. R. Soc. Lond. B Biol. Sci. 358: 1741-1753.

Beekman M, Komdeur J and Ratnieks FLW (2003). Reproductive conflicts in social animals: who has power? Trends Ecol. Evol. 18: 277-282.

Beig D (1972). The production of males in queenright colonies of Trigona (Scaptotrigona) postica. J. Apic. Res. 11: 33-39.

Benford FA (1978). Fisher's theory of the sex ratio applied to the social Hymenoptera. J. Theor. Biol. 72: 701-727.

Boomsma JJ (1989). Sex-investment ratios in ants: has female bias been systematically overestimated? Am. Nat. 133: $517-532$.

Boomsma JJ and Grafen A (1990). Intra-specific variation in ant sex ratios and the Trivers-Hare hypothesis. Evolution 4: 1026-1034.

Boosma JJ and Grafen A (1991). Colony-level sex-investment ratios in eusocial insects. J. Evol. Biol. 3: 383-407.

Boomsma JJ, Baer B and Heinze J (2005). The evolution of male traits in social insects. Annu. Rev. Entomol. 50: 395-420.

Bourke AFG (1999). Colony size, social complexity and reproductive conflict in social insects. J. Evol. Biol. 12: 245-257.

Bourke AFG and Franks NR (1995). Social Evolution in Ants. Princeton Univ. Press, Princeton.

Bourke AFG and Ratnieks FLW (1999). Kin conflict over caste determination in social Hymenoptera. Behav. Ecol. 
Sociobiol. 46: 287-297.

Bourke AF and Chan GL (1999). Queen-worker conflict over sexual production and colony maintenance in perennial social insects. Am. Nat. 154: 417-426.

Cameron EC, Franck P and Oldroyd BP (2004). Genetic structure of nest aggregations and drone congregations of the southeast Asian stingless bee Trigona collina. Mol. Ecol. 13: 2357-2364.

Cepeda OI (2006). Division of labor during brood production in stingless bees with special reference to individual participation. Apidologie 37: 175-190.

Chapuis M and Keller L (1999). Testing kin selection with sex allocation data in eusocial Hymenoptera. Heredity 82 (Pt 5): 473-478.

Charnov EL (1978). Sex-ratio selection in eusocial Hymenoptera. Am. Nat. 112: 317-326.

Cole BJ (1986). The social behaviour of Leptothorax allardycei (Hymenoptera, Formicidae): Time budgets and the evolution of worker reproduction. Behav. Ecol. Sociobiol. 18: 165-173.

Crozier RH and Pamilo P (1996). Evolution of Social Insect Colonies Sex Allocation and Kin Selection. Oxford University Press, New York.

Eltz T, Brühl CA, van der Kaars S and Linsenmair KE (2002). Determinants of stingless bee nest density in lowland dipterocarp forests of Sabah, Malaysia. Oecologia 131: 27-34.

Eltz T, Brühl CA, Imiyabir Z and Linsenmair KE (2003). Nesting and nest trees of stingless bees (Apidae: Meliponini) in lowland dipterocarp forests in Sabah, Malaysia, with implications for forest management. Forest Ecol. Manag. 172: 301-313.

Fisher RA (1958). The Genetical Theory of Natural Selection. 2nd edn. Dover, New York.

Foster KR and Ratnieks FL (2001). The effect of sex-allocation biasing on the evolution of worker policing in hymenopteran societies. Am. Nat. 158: 615-623.

Frank SA (1987). Individual and population sex allocation patterns. Theor. Popul. Biol. 31: 47-74.

Frank SA (1998) Foundations of Social Evolution. Princeton University Press, New Jersey.

Grafen A (1990). Do animals really recognize kin? Anim. Behav. 39: 42-54.

Hamilton WD (1964). The genetical evolution of social behaviour. I. J. Theor. Biol. 7: 1-16.

Hamilton WD (1972). Altruism and related phenomena, mainly in social insects. Ann. Rev. Ecol. Syst. 3: 193-232.

Hammond RL and Keller L (2004). Conflict over male parentage in social insects. PLoS Biol. 2: E248.

Hammond RL, Bruford MW and Bourke AF (2003). Male parentage does not vary with colony kin structure in a multiplequeen ant. J. Evol. Biol. 16: 446-455.

Helms KR, Reuter M and Keller L (2005). Sex-ratio conflict between queens and workers in eusocial Hymenoptera: mechanisms, costs, and the evolution of split colony sex ratios. Evolution 59: 2626-2638.

Herbers JM (1979). The evolution of sex ratio strategies in hymenopteran societies. Am. Nat. 114: 818-834.

Inoue T, Hamid AA and Yamane S (1984). The process of colony multiplication in the Sumatran stingless bee Trigona (Tetragonula) laeviceps. Biotropica 16: 100-111.

Inoue T, Nakamura K, Salmah S and Abbas I (1993). Population dynamics of animals in unpredictably-changing tropical environments. J. Biosc. 18: 425-455.

Inoue T, Roubik DW and Suka T (1999). Nestmate recognition in the stingless bee Melipona panamica (Apidae, Meliponini). Insectes Soc. 46: 208-218.

Keller L (1997). Indiscriminate altruism: unduly nice parents and siblings. Trends Ecol. Evol. 12: 99-103.

Kerr WE and Vencovsky R (1982). Melhoramento genético em abelhas I. Efeito de número de colônias sobre o melhoramento. Rev. Bras. Genet. 5: 279-285.

Koedam D, Contrera FAL, Fidalgo AO and Imperatriz-Fonseca VL (2005). How queen workers share in male production in the stingless bee Melipona subnitida Ducke (Apidae, Meliponini). Insectes Soc. 52: 114-121.

Koedam D, Cepeda Aponte OI and Imperatriz-Fonseca VL (2007). Egg laying and oophagy by reproductive workers in the polygynous stingless bee Melipona bicolor (Hymenoptera, Meliponini). Apidologie 38: 55-66.

Lin N and Michener CD (1972). Evolution of sociality in insects. Q. Rev. Biol. 47: 131-159.

Matessi C and Eshel (1992). Sex ratio in the social Hymenoptera: a population-genetics study of long-term evolution. $\mathrm{Am}$. Nat. 139: 276-312.

Mehdiabadi NJ, Reeve HK and Mueller UG (2003). Queens versus workers: sex-ratio conflict in eusocial Hymenoptera. Trends Ecol. Evol. 18: 88-93.

Nogueira-Neto P (1954). Notas bionômicas sobre Meliponíneos: III. Sobre a enxameagem. Arq. Mus. Nac. 42: 419-451. Nonacs P (1986). Ant reproductive strategies and sex allocation theory. Q. Rev. Biol. 61: 1-21.

Oster GF and Wilson EO (1978). Caste and Ecology in the Social Insects. Princeton University Press, New Jersey.

Pamilo P (1990). Sex allocation and queen-worker conflict in polygynous ants. Behav. Ecol. Sociobiol. 27: 31-36.

Pamilo P (1991a). Evolution of colony characteristics in social insects, I. Sex allocation. Am. Nat. 137: 83-107. 
Pamilo P (1991b). Evolution of colony characteristics in social insects. II. Number of reproductive individuals. Am. Nat. 138: $412-433$.

Paxton RJ (2005). Male mating behaviour and mating systems of bees: an overview. Apidologie 36: 145-156.

Peters JM, Queller DC, Imperatriz-Fonseca VL, Roubik DW, et al. (1999). Mate number, kin selection and social conflicts in stingless bees and honeybees. Proc. Biol. Sci. 266: 379-384.

Ratnieks FLW and Reeve HK (1992). Conflict in single queen Hymenopteran societies: the structure of conflict and processes that reduce conflict in advanced eusocial species. J. Theor. Biol. 158: 33-65.

Ratnieks FLW and Boomsma JJ (1997). On the robustness of split sex ratio predictions in social Hymenoptera. J. Theor. Biol. 185: 423-439.

Ratnieks FL, Foster KR and Wenseleers T (2006). Conflict resolution in insect societies. Annu. Rev. Entomol. 51: 581-608.

Reuter M and Keller L (2001). Sex ratio conflict and worker production in eusocial Hymenoptera. Am. Nat. 158: 166-177.

Reuter M, Helms KR, Lehmann L and Keller L (2004). Effects of brood manipulation costs on optimal sex allocation in social Hymenoptera. Am. Nat. 164: E73-E82.

Roisin Y and Aron S (2003). Split sex ratios in perennial social Hymenoptera: a mixed evolutionary stable strategy from the queens' perspective? Am. Nat. 162: 624-637.

Santos-Filho PS, Alves DA, Eterovic A, Imperatriz-Fonseca VL, et al. (2006). Numerical investment in sex and caste by stingless bees (Apidae: Meliponini): a comparative analysis. Apidologie 37: 207-221.

Strassmann J (2001). The rarity of multiple mating by females in the social Hymenoptera. Insectes Soc. 48: 1-13.

Tambasco AJ (1971). Processo reprodutivo em Melipona quadrifasciata e seu impacto na população geneticamente ativa. Cienc. Cult. 23: 104-105.

Tóth E, Queller D, Dollin A and Strassmann J (2004). Conflict over male parentage in stingless bees. Insectes Soc. 51: 1-11.

Trivers RL (1974). Parent-offspring conflict. Am. Zool. 14: 249-264.

Trivers RL and Hare H (1976). Haplodiploidy and the evolution of the social insect. Science 191: 249-263.

Velthuis HHW, Koedam D and Imperatriz-Fonseca VL (2005). The males of Melipona and other stingless bees, and their mothers. Apidologie 36: 169-185.

Wenseleers T and Ratnieks FL (2006). Comparative analysis of worker reproduction and policing in eusocial Hymenoptera supports relatedness theory. Am. Nat. 168: E163-E179.

Wenseleers T, Hart AG and Ratnieks FLW (2004a). When resistance is useless: policing and the evolution of reproductive acquiescence in insect societie. Am. Nat. 64: E154-E167.

Wenseleers T, Helantera H, Hart AG and Ratnieks FLW (2004b). Worker reproduction and policing in insect societies: an ESS analysis. J. Evol. Biol. 17: 1035-1047.

Wilson EO (1971). The Insect Societies. Harvard University Press, Cambridge.

Woyciechowski M and Lomnicki A (1987). Multiple mating of queens and the sterility of workers among eusocial Hymenoptera. J. Theor. Biol. 128: 317-327. 